\title{
What is new in non-ventilated ICU-acquired pneumonia?
}

\author{
Wafa Ibn Saied ${ }^{1 *}$, Ignacio Martin-Loeches ${ }^{2,3,4}$ and Jean-François Timsit ${ }^{1,5}$
}

(c) 2020 Springer-Verlag GmbH Germany, part of Springer Nature

Guidelines and recommendations for non-ventilated hospital-acquired pneumonia (NV-HAP) are typically based on the research from ventilator-associated pneumonia (VAP) $[1,2]$. Data for non-ventilated intensive care unit (ICU) patients with nosocomial pneumonia (NV-ICUAP) are scarce (Fig. 1). The current manuscript aims to elucidate whether these conditions are similar or different clinical entities.

\section{Incidence and physiopathology}

The overall incidence of non-ventilated (NV)-HAP has been reported to affect $1.3-1.6 \%$ patients, equivalent to a rate of 3.63 per 1000 patient-days [3]. Only one recent study provided an estimate of the incidence of NVICUAP of 4.5 per 1000 patient-ICU-days as compared to an incidence of VAP of 21 per 1000 invasive mechanical ventilation days [4] (Fig. 1). The mechanisms by which the microorganisms may enter into the respiratory tract are multifactorial via a direct colonization from the oropharynx, via aspiration of the gastric flora, or via haematological dissemination from distant septic foci. Depressed consciousness with micro-aspiration, lack of cough reflex with an effective cough and alteration in gastric motility are the most likely mechanisms of colonization of the lower respiratory tract (Fig. 1). Delayed intubation due to prolonged use of non-invasive ventilation and high-flow oxygenation may increase the risk of intubation-related complications and subsequent ICUHAP in some patients [5].

\footnotetext{
*Correspondence: essaied.wafa@gmail.com

${ }^{1}$ University of Paris, IAME, INSERM, 75018 Paris, France

Full author information is available at the end of the article
}

\section{Clinical suspicion and challenges of microbial confirmation}

Many infectious and non-infectious diseases may cause fever and impaired oxygenation complicating the diagnosis of NV-ICUAP [6]. A recent study using the Delphi method suggested that the main clinical/biological features to diagnose NV-ICUAP (73\% final agreement) were: worsening gas exchange, fever or hypothermia, purulent tracheal secretions, dyspnoea, leucocytosis or leucopenia, and hypotension and/or vasopressor requirements [7]. The clinical pulmonary infection score (CPIS) $>6$ showed a sensitivity of $42 \%$ (95\% CI $29-26 \%)$ and a specificity of $87 \%$ (95\% CI $74-95 \%)$ for the diagnosis of HAP [8], eventually not retained by a group of expert panellists.

Furthermore, the sensitivity of chest X-rays occurs in no more than two-thirds of patients diagnosed by NVHAP [9]. The repeated lung ultrasound examination to detect new pulmonary infiltrates has been suggested as an useful tool in ventilated patients (with a sensitivity of 94\% (95\% CI 92-96\%) and a specificity of 96\% (95\% CI 94-97\%) [10]. Its use in NV-ICUAP diagnosis remains to be further evaluated.

Another important problem is to determine the aetiology in NV-ICUAP patients. Previous studies have shown that distal quantitative samples (collected prior to starting any antibiotic treatment) in patients with suspected VAP improved the accuracy of the results and reduced antibiotic exposure [1]. However, in the vast majority of non-ventilated patients, this approach is often feasible. For them, two diagnostic strategies remain: (1) non-invasive samplings with immediate empirical antibiotic treatment and (2) protected brush sampling of specimens. Both strategies have been compared in a randomized single-centre study in patients with HAP not admitted to an ICU. Whilst both approaches had similar mortality rates and overall management costs, the cost for antibiotic

\section{实 Springer}




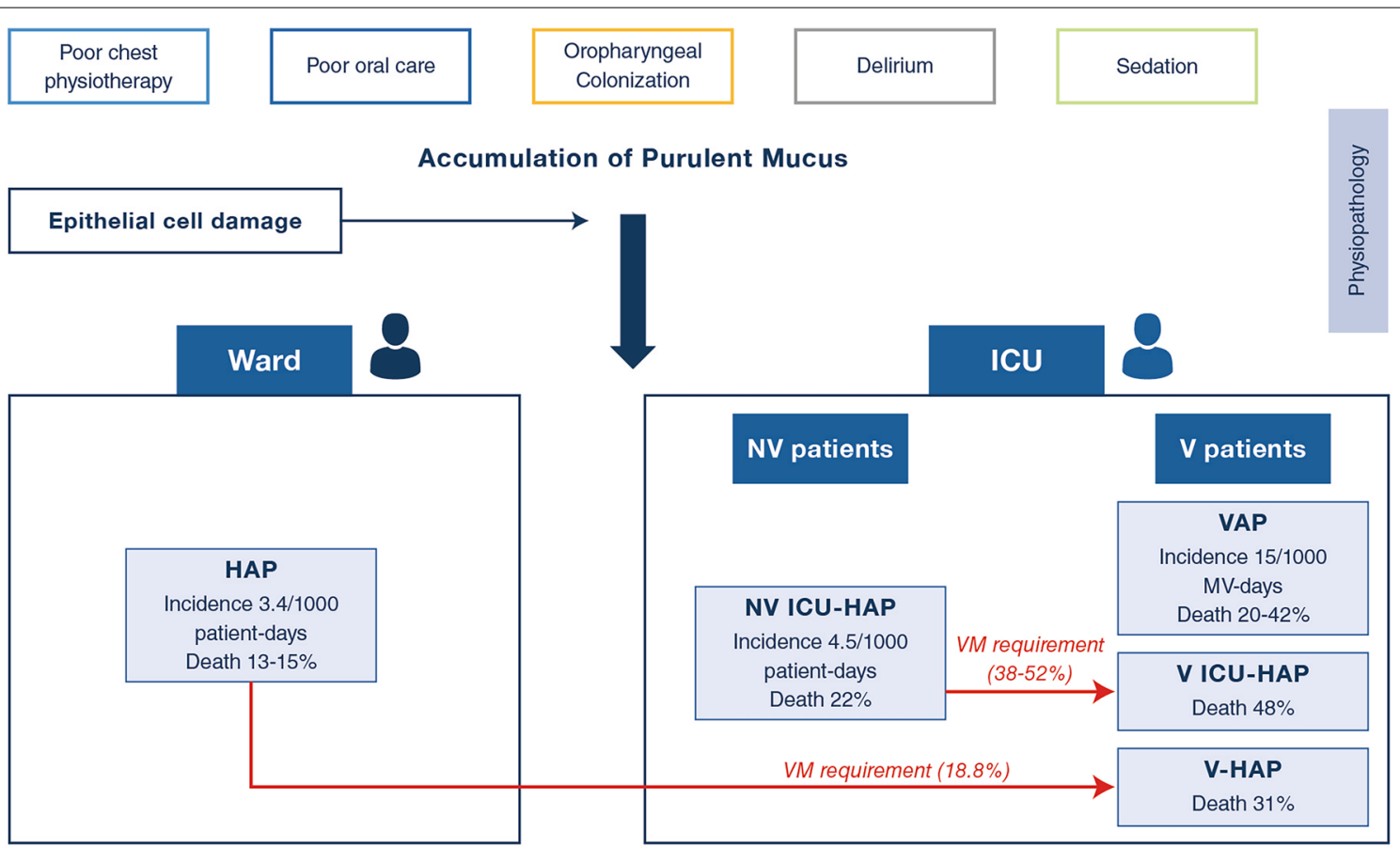

Fig. 1 Spectrum of nosocomial pneumonia hospitalized in ICU. Legends: V: invasively ventilated; NV: non invasively ventilated patients; MV: invasive mechanical ventilation

treatment was lower in the brush sampling group [11]. In addition, the invasive approach appeared to carry a lower risk of immunosuppressed patients with acute respiratory failure (ARF) if performed in ICU under appropriate surveillance, oxygenation, and non-invasive ventilation (when required) [12]. Under these conditions, the invasive strategy can lead to a more accurate aetiology and to improving the implementation of targeted therapy in non-ventilated immunocompromised patients with pulmonary infiltrates (not necessarily pneumonia) [12]. However, it remains unclear whether invasive approaches are associated with improvements in patient outcomes in NV-ICUAP. The 2016 Infectious Diseases Society of America (IDSA) and the American Thoracic Society (ATS) guidelines recommended non-invasive respiratory sampling in patient with suspicion of HAP, although the panel agreed that there may be risk factors that prompt clinicians to consider invasive sampling [2]. Ranzani et al. compared different diagnostic approaches used in different ICU-HAP cohorts and highlighted the utility of sputum and distal sampling in HAP [8]. In fact, sputum sampling was responsible for one-third of the final aetiology diagnosed in HAP patients who were not subsequently intubated. It is unclear whether invasive approaches [e.g. bronchoalveolar lavage (BAL)] are associated with an improvement in patients' outcomes, and further research is needed to ensure their correct indication whilst guaranteeing patient safety. The role of rapid diagnostic methods from sputum and tracheal aspirate of distal respiratory sample for rapid detection of viruses, bacteria, and resistance mechanisms remains to be evaluated, but it seems to be a promising tool. We suggest a diagnostic algorithm in Supplementary Figure E1 balancing non-invasive and invasive procedures.

\section{Antimicrobial therapy}

Available studies found similar pathogens isolated in VAP and NV-ICUAP (even with similar previous duration of stay) $[4,13]$. Therefore, European and US guidelines suggested empirical administration of broad-spectrum antibiotics in VAP and NV-ICUAP, even when the aetiology is uncertain $[2,14]$.

New rapid molecular techniques for the detection of viruses in blood, sputum, or nasopharyngeal (NP) swabs could be helpful diagnostic tools, especially for NV-ICUAP $[14,15]$. Viruses such as respiratory syncytial virus (RSV), rhinovirus, influenza, and parainfluenza should be considered as culprit pathogens recovered in a significant proportion of cases $[15,16]$. New multiplex polymerase chain reaction $(\mathrm{PCR})$ respiratory-based panels combining viral, bacterial (including bacterial resistance pattern detection) are an important diagnostic option that remained to be evaluated for NV-ICUAP. Nevertheless, PCR-based techniques for guiding early 
documented therapy and de-escalation still remain to be evaluated [16].

\section{Prognosis and prevention}

Studies have identified that the occurrence of HAP outside the ICU is associated with increased mortality and length of hospital stay and leads to ICU admission in one out of five cases $[9,15]$. For ICU patients, mortality was similar in NV-ICUAP and VAP, suggesting that risk factors "per se" are the main determinants of the patients' outcome $[4,17]$. A recent multicentre cohort study found that NV-ICUAP needed intubation within $48 \mathrm{~h}$ in $38 \%$ of the cases and showed an impressive $82 \%$ increase in the risk of mortality within 30 days whilst the same increase for VAP patients was only $38 \%$ [4]. Further multicentre studies using accepted definition are required to better define the morbi-mortality and risk factors for poor outcome.

Most of the strategies to prevent NV-ICUAP are unproven. Hand hygiene, early mobilization, and respiratory physiotherapy appear reasonable. Recent cohort suggests the harmful effect of oral chlorhexidine in NV patients [18]. Therefore, ERS/ESCIM/ESCMID/ ALAT guidelines fell short of any formal recommendations on the general use of chlorhexidine oral decontamination. The use of selective oral decontamination (SOD) with topical antibiotics in ICU settings with low rates of antimicrobial resistance and low antibiotic use has been also suggested although its impact on NVICUAP has not been yet demonstrated to have a clinical benefit.

\section{Concluding remarks: NV-ICUAP: a life threatening pathology that requires future research}

Available data suggest that NV-ICUAP is frequent and impairs prognosis possibly because of late diagnosis and imprecise prevention strategies. Further research is urgently needed in many fields to improve our knowledge, skill, and patients' outcome. There are several main areas of research: (1) to improve the detection of infection and aetiology of the respiratory infection; (2) to assess the role of lung US to diagnose a new infiltrate; (3) to assess whether the implementation of invasive techniques (fiberoptic bronchoscopy with BAL) will improve diagnostic accuracy and microbiological confirmation that ultimately will provide an early adequate antimicrobial therapy and an improvement in patients' prognosis; (4) to assess the role of early detection of viruses in NV-ICUAP and the possible impact of passive or active immunization; (5) to evaluate the right timing for intubation when non-invasive ventilation and/or high flow is being used and not improving the patient's clinical condition; and (6) to evaluate the impact of oral care with chlorhexidine and SOD in NV patients.

\section{Electronic supplementary material}

The online version of this article (https://doi.org/10.1007/s00134-019-05859-9) contains supplementary material, which is available to authorized users.

\section{Abbreviations}

HAP: Hospital-acquired pneumonia; NV-ICUAP: Non-ventilated ICU-acquired pneumonia; VAP: Ventilator-associated pneumonia.

\section{Author details}

${ }^{1}$ University of Paris, IAME, INSERM, 75018 Paris, France. ${ }^{2}$ Department of Anaesthesia and Critical Care Medicine, St. James's Hospital, Dublin, Ireland. ${ }^{3}$ Multidisciplinary Intensive Care Research Organization (MICRO), St James's Hospital, Dublin, Ireland. ${ }^{4}$ Pulmonary Intensive Care Unit, Respiratory Institute, Hospital Clinic of Barcelona, IDIBAPS, University of Barcelona, Barcelona, Spain. ${ }^{5}$ AP-HP, Bichat Hospital, Medical and Infectious Diseases ICU (MI2), 75018 Paris, France.

\section{Compliance with ethical standards}

\section{Conflicts of interest}

The authors declare that they have no conflict of interest.

\section{Publisher's Note}

Springer Nature remains neutral with regard to jurisdictional claims in published maps and institutional affiliations.

Received: 25 July 2019 Accepted: 7 November 2019

Published online: 14 January 2020

\section{References}

1. Torres A, Niederman MS, Chastre J, Ewig S, Fernandez-Vandellos $P$, Hanberger H, Kollef M, Li Bassi G, Luna CM, Martin-Loeches I, Paiva JA, Read RC, Rigau D, Timsit JF, Welte T, Wunderink R (2017) International ERS/ESICM/ESCMID/ALAT guidelines for the management of hospitalacquired pneumonia and ventilator-associated pneumonia: guidelines for the management of hospital-acquired pneumonia (HAP)/ventilatorassociated pneumonia (VAP) of the European Respiratory Society (ERS), European Society of Intensive Care Medicine (ESICM), European Society of Clinical Microbiology and Infectious Diseases (ESCMID) and Asociacion Latinoamericana del Torax (ALAT). Eur Respir J 50:00582-02017

2. Kalil AC, Metersky ML, Klompas M, Muscedere J, Sweeney DA, Palmer LB, Napolitano LM, O'Grady NP, Bartlett JG, Carratala J, El Solh AA, Ewig S, Fey PD, File TM Jr, Restrepo MI, Roberts JA, Waterer GW, Cruse P, Knight SL, Brozek JL (2016) Management of adults with hospital-acquired and ventilator-associated pneumonia: 2016 clinical practice guidelines by the Infectious Diseases Society of America and the American Thoracic Society. Clin Infect Dis 63:e61-e111

3. Giuliano KK, Baker D, Quinn B (2018) The epidemiology of nonventilator hospital-acquired pneumonia in the United States. Am J Infect Control 46:322-327

4. Ibn Saied W, Mourvillier B, Cohen Y, Ruckly S, Reignier J, Marcotte G, Siami S, Bouadma L, Darmon M, de Montmollin E, Argaud L, Kallel H, GarrousteOrgeas M, Soufir L, Schwebel C, Souweine B, Glodgran-Toledano D, Papazian L, Timsit JF (2019) A comparison of the mortality risk associated with ventilator-acquired bacterial pneumonia and nonventilator ICU-acquired bacterial pneumonia. Crit Care Med 47:345-352

5. Mosier JM, Sakles JC, Whitmore SP, Hypes CD, Hallett DK, Hawbaker KE, Snyder LS, Bloom JW (2015) Failed noninvasive positive-pressure ventilation is associated with an increased risk of intubation-related complications. Ann Intensive Care 5:015-0044

6. Ferrer M, Torres A (2018) Epidemiology of ICU-acquired pneumonia. Curr Opin Crit Care 24:325-331 
7. Weiss E, Zahar J-R, Alder J, Asehnoune K, Bassetti M, Bonten MJM, Chastre J, De Waele J, Dimopoulos G, Eggimann P, Engelhardt M, Ewig S, Kollef M, Lipman J, Luna C, Martin-Loeches I, Pagani L, Palmer LB, Papazian L, Poulakou G, Prokocimer P, Rello J, Rex JH, Shorr AF, Talbot GH, Thamlikitkul V, Torres A, Wunderink RG, Timsit J-F (2019) Elaboration of consensus clinical endpoints to evaluate antimicrobial treatment efficacy in future hospitalacquired/ventilator-associated bacterial pneumonia clinical trials. Clin Infect Dis 69(11):1912-1918. https://doi.org/10.1093/cid/ciz093

8. Ranzani OT, Senussi T, Idone F, Ceccato A, Li Bassi G, Ferrer M, Torres A (2019) Invasive and non-invasive diagnostic approaches for microbiological diagnosis of hospital-acquired pneumonia. Crit Care 23:019-2348

9. Russell CD, Koch O, Laurenson IF, O'Shea DT, Sutherland R, Mackintosh $C L$ (2016) Diagnosis and features of hospital-acquired pneumonia: a retrospective cohort study. J Hosp Infect 92:273-279

10. Chavez MA, Shams N, Ellington LE, Naithani N, Gilman RH, Steinhoff MC, Santosham M, Black RE, Price C, Gross M, Checkley W (2014) Lung ultrasound for the diagnosis of pneumonia in adults: a systematic review and meta-analysis. Respir Res 15:1465-9921

11. Herer B, Fuhrman C, Gazevic Z, Cabrit R, Chouaid C (2009) Management of nosocomial pneumonia on a medical ward: a comparative study of outcomes and costs of invasive procedures. Clin Microbiol Infect 15:165-172

12. Azoulay E, Mokart D, Lambert J, Lemiale V, Rabbat A, Kouatchet $A$, Vincent F, Gruson D, Bruneel F, Epinette-Branche G, Lafabrie A, Hamidfar-Roy R,
Cracco C, Renard B, Tonnelier JM, Blot F, Chevret S, Schlemmer B (2010) Diagnostic strategy for hematology and oncology patients with acute respiratory failure: randomized controlled trial. Am J Respir Crit Care Med 182:1038-1046

13. Esperatti M, Ferrer M, Theessen A, Liapikou A, Valencia M, Saucedo LM, Zavala E, Welte T, Torres A (2010) Nosocomial pneumonia in the intensive care unit acquired by mechanically ventilated versus nonventilated patients. Am J Respir Crit Care Med 182:1533-1539

14. Timsit JF, Bassetti M, Cremer O, Daikos G, de Waele J, Kallil A, Kipnis E, Kollef M, Laupland K, Paiva JA, Rodriguez-Bano J, Ruppe E, Salluh J, Taccone FS, Weiss E, Barbier F (2019) Rationalizing antimicrobial therapy in the ICU: a narrative review. Intensive Care Med 45:172-189

15. Micek ST, Chew B, Hampton N, Kollef MH (2016) A case-control study assessing the impact of nonventilated hospital-acquired pneumonia on patient outcomes. Chest 150:1008-1014

16. Shorr AF, Zilberberg MD, Micek ST, Kollef MH (2017) Viruses are prevalent in non-ventilated hospital-acquired pneumonia. Respir Med 122:76-80

17. Esperatti M, Ferrer M, Giunta V, Ranzani OT, Saucedo LM, Li Bassi G, Blasi F, Rello J, Niederman MS, Torres A (2013) Validation of predictors of adverse outcomes in hospital-acquired pneumonia in the ICU. Crit Care Med 41:2151-2161

18. Deschepper M, Waegeman W, Eeckloo K, Vogelaers D, Blot S (2018) Effects of chlorhexidine gluconate oral care on hospital mortality: a hospitalwide, observational cohort study. Intensive Care Med 44:1017-1026 